\title{
A Method for Internal Curing Water Calculation of Concrete with Super Absorbent Polymer
}

\author{
Shouqi Zhang $\mathbb{D D}^{1,2,3}$ Zhenbao Lu $\mathbb{D}^{2,3}$ Yongxin Li $\mathbb{D}^{2,3}$ Yuan Ang $\mathbb{D},^{2,3}$ \\ and Kechao Zhang $\mathbb{B D}^{2,3,4}$ \\ ${ }^{1}$ Southeast University, Nanjing 211189, China \\ ${ }^{2}$ Research and Development Center of Transport Industry of Intelligent Manufacturing Technologies of Transport \\ Infrastructure Ministry of Transport, PRC, China-road Transportation Verification \& Inspection Hi-Tech Co., Ltd., \\ Beijing 100088, China \\ ${ }^{3}$ Research Institute of Highway Ministry of Transport, Beijing 100088, China \\ ${ }^{4}$ School Civil Engineering, Chongqing University, Chongqing 400044, China
}

Correspondence should be addressed to Shouqi Zhang; shouqi.zhang@ctvic.cn

Received 5 November 2020; Revised 8 March 2021; Accepted 24 March 2021; Published 9 April 2021

Academic Editor: Qian Zhang

Copyright ( $(2021$ Shouqi Zhang et al. This is an open access article distributed under the Creative Commons Attribution License, which permits unrestricted use, distribution, and reproduction in any medium, provided the original work is properly cited.

The internal curing method is effective in reducing the self-desiccation of concrete, and the amount of internal curing water (IC water) is greatly important to the shrinkage and strength of concrete. A method for calculating IC water of concrete with and without mineral admixture has been developed. The method is derived from Powers' model for the phase distribution of a hydrating cement paste. To verify the method, a series of autogenous shrinkage and compressive strength of concrete with and without super absorbent polymer (SAP) were evaluated compared with the method proposed previously. To explain the macro performance of hardened concrete, the nonevaporable water content and calcium hydroxide content measurement were utilized to evaluate the degree of hydration of cement pastes. And, mercury intrusion method and image analysis method were used to explore the pore structure in hardened cement pastes and air void characteristics in hardened concrete, respectively. Furthermore, the evolution process was also studied for the relative humidity inside the concrete.

\section{Introduction}

It has been widely known that cement hardening is a chemical reaction essentially. Free water is consumed during the chemical reaction. For concrete with a higher water to cement ratio $(w / c$ ratio), the consumed water will be supplemented from the close region, while in concrete with a lower $w / c$ ratio, water is insufficient. As a result, self-desiccation will occur [1].

High-strength concrete (HSC) achieves high strength with a low $w / c$ ratio commonly, which has been widely used in construction fields such as high-rise buildings and long-span bridges. Self-desiccation increases the capillary pore pressure as water is consumed in the hydration process and relative humidity is decreased in cementitious materials [2-4]. The increase in capillary pressure generates a shrinkage deformation in the solid skeleton of cementitious materials, which ultimately leads to the volume deformation of HSC, named autogenous shrinkage $[5,6]$. Autogenous shrinkage is one of the significant causes of cracks in early age hardened HSC with a negative impact on its durability $[7,8]$.

The conventional external curing methods, such as watering and covering with wet burlap, are widely used and introduced to technical specifications. However, for HSC with low porosity and permeability, the conventional external curing methods are not effective, because the external curing water penetrates only the surface layer of the HSC. The internal curing method is developed to provide additional moisture inside the concrete for reducing self-desiccation. When the water content is decreased in the pore structure, with a high water absorption capacity, the internal curing agent releases water into its surrounding region in the cementitious microstructure, to maintain a high relative humidity [9]. 
One of the effective internal curing methods is internalcuring concrete with super absorbent polymer (SAP) [10]. SAP is a new type of functional polymer material that can absorb several tens of times of water compared with its mass. The incorporation of SAP releases water, which can improve internal humidity in concrete.

The autogenous shrinkage reduction is confirmed by some researchers, while the mechanical strength is not [11-13]. According to some studies, the addition of SAP is often found to hurt mechanical strength of the hardened cementitious materials [4, 14], while some other studies report enhancement in compressive strength by the addition of SAP $[15,16]$. It is worthy to note that the effect of SAP on the performance of cementitious materials depends on not only the molecular structure, particle size distribution, dosage, and absorption/desorption behavior of SAP but also on the amount of IC water and concrete mix proportion $[15,17]$.

The amount of IC water is greatly important to shrinkage and strength, because it may affect the water and cement ratio $(w / c)$ change, which is one of the crucial parameters in concrete mix proportion. Based on the Powers' model, Jensen proposed a calculation method of IC water for cement paste without mineral admixture, as shown in[7]:

$$
\begin{aligned}
\left(\frac{w}{c}\right)_{i} & =0.18\left(\frac{w}{c}\right), \\
\frac{w}{c} & \leq 0.36, \\
\frac{w}{c}+\left(\frac{w}{c}\right)_{i} & =0.42, \\
0.36 & <\frac{w}{c} \leq 0.42 .
\end{aligned}
$$

It is important to estimate the IC water by calculating chemical shrinkage accurately, and then the additional water is used to fill the space left by chemical shrinkage. According to Jensen's researches, the hydrated microstructure space was completely occupied by three phases: gel solid, gel water, and unreacted cement particles. Nevertheless, the volume of the system cannot be steady before and after cement hydration, and shrinkage must be had. On the other hand, mineral admixtures can change the hydration characteristics and microstructure of concrete such as fly ash (FA), granulated ground blast furnace slag (GGBS), and silica fume (SF) [18]. Then, they can significantly change the chemical shrinkage of concrete. However, the IC water calculation method as shown in equations (1) and (2) is not the modification for mineral admixtures.

To make the IC water more accurately, a developed method for calculating IC water with and without FA is proposed. According to this method, the effects of internal curing with SAP on autogenous shrinkage and compressive strength of concrete with and without FA are discussed. Furthermore, the degree of hydration of cement pastes, the pore structure of concrete, and the relative humidity inside concrete are evaluated to explain the observed results.

\section{IC Water Calculating Method}

2.1. Concrete without Mineral Admixture. To calculate the IC water of concrete quantitatively, it is necessary to determine the chemical shrinkage of cement hydration. In Powers' model $[19,20]$, water held in hardened cement paste can be divided into three phases: capillary water, gel water, and chemically bound water. $1 \mathrm{~g}$ cement can combine with about $0.23 \mathrm{~g}$ water when it reacts completely and forms C-S-H gel. This part of the water is called chemically bound water, which can release only in the condition of over $105^{\circ} \mathrm{C}$. As $\mathrm{C}-\mathrm{S}-\mathrm{H}$ gel is the solid phase with a large specific surface area, $0.19 \mathrm{~g}$ water can be adsorbed to the surface, named gel water. Gel water is combined physically, the content of which corresponds to the relative humidity (0-100\%) inside the concrete. In addition to chemically bound water and gel water, residual water forms capillary pore water or free water, which exists in capillary pores (greater than $5 \mathrm{~nm}$ ). The volume of cement hydration products is smaller than the volume of cement and water involved in the reaction, that is, chemical shrinkage. When the cement hydrates completely, the quantity of chemical shrinkage is about $6.4 \mathrm{ml} / 100 \mathrm{~g}$ cement.

Based on the above three key values, the volume calculation model of chemical shrinkage, hydration products, and unhydrated cement can be described by Powers as shown in

$$
\begin{aligned}
V_{\mathrm{cs}} & =6.4 \times 10^{-5} \rho_{\mathrm{c}}(1-p) \alpha=0.20(1-p) \alpha, \\
V_{\mathrm{cw}} & =p-\left(\frac{\rho_{\mathrm{c}}}{\rho_{\mathrm{w}}}\right)(0.19+0.23)(1-p) \alpha=p-1.32(1-p) \alpha,
\end{aligned}
$$

$$
\begin{aligned}
V_{\mathrm{gw}} & =\left(\frac{\rho_{\mathrm{c}}}{\rho_{\mathrm{w}}}\right) 0.19(1-p) \alpha=0.60(1-p) \alpha \\
V_{\mathrm{gs}} & =\left(1-6.4 \times 10^{-5} \rho_{\mathrm{c}}+0.23\left(\frac{\rho_{\mathrm{c}}}{\rho_{\mathrm{w}}}\right)\right)(1-p) \alpha \\
& =1.52(1-p) \alpha \\
V_{\mathrm{uc}} & =(1-p)(1-\alpha) \\
p & =\frac{(w / c)}{\left(w / c+t \rho_{\mathrm{w}} / \rho_{\mathrm{c}}\right)}
\end{aligned}
$$

where $V_{c s}$ is the relative volume fraction $\left(\mathrm{m}^{3} / \mathrm{m}^{3}\right.$ cement paste) of chemical shrinkage; $V_{\mathrm{cw}}$ is the relative volume fraction $\left(\mathrm{m}^{3} / \mathrm{m}^{3}\right.$ cement paste) of capillary water; $V_{\mathrm{gw}}$ is the relative volume fraction $\left(\mathrm{m}^{3} / \mathrm{m}^{3}\right.$ cement paste) of gel water; $V_{\mathrm{gs}}$ is the relative volume fraction $\left(\mathrm{m}^{3} / \mathrm{m}^{3}\right.$ cement paste) of gel solid; $V_{\mathrm{uc}}$ is the relative volume fraction $\left(\mathrm{m}^{3} / \mathrm{m}^{3}\right.$ cement paste) of unhydrated cement; $\alpha$ is the degree of hydration $(\mathrm{kg}$ cement reacted $/ \mathrm{kg}$ initial cement); $\rho_{\mathrm{c}}=3150 \mathrm{~kg} / \mathrm{m}^{3}$ the cement density; $\rho_{\mathrm{w}}=1000 \mathrm{~kg} / \mathrm{m}^{3}$ the water density; $p$ is the initial porosity; and $w / c$ is the water/cement ratio $(\mathrm{kg} / \mathrm{kg})$. 
In the process of cement hydration, capillary water continues to provide reaction water for cement hydration. When the capillary water is exhausted, the relative humidity inside the cement paste decreases, resulting in the slowing or even stopping of cement hydration. When cement hydrates completely, $1 \mathrm{~g}$ cement consumes $0.23 \mathrm{~g}$ chemically bound water and $0.19 \mathrm{~g}$ gel water, indicating that the lowest $w / c$ ratio is $0.42(0.23+0.19)$. When the $w / c$ ratio is lower than 0.42 , there will be unhydrated cement particles in the cement paste, and with the decrease of internal relative humidity, self-desiccation will occur, resulting in irreversible autogenous shrinkage.

To quantify the volume content of composition in hydrated cement structure, Powers assumed that gel water did not participate in cement hydration [21]. Based on this assumption, in this study, the volume change caused by chemical shrinkage is taken into account for calculating the total volume. Thereby, hydration microstructure is completely occupied by four phases, namely, gel solid, gel water, unhydrated cement particles and chemical shrinkage when the hydration of cement reaches the maximum. The expression of the maximum hydration degree of cement is shown in

$$
\begin{aligned}
V_{\mathrm{gw}}+V_{\mathrm{gs}}+V_{\mathrm{uc}}+V_{\mathrm{cs}} & =1, \\
\alpha & =\alpha_{\max } .
\end{aligned}
$$

Introduce equations (3), (5)-(7) into equation (9):

$$
\begin{aligned}
0.60(1-p) \alpha_{\max }+1.52(1-p) \alpha_{\max }+(1-p)\left(1-\alpha_{\max }\right) \\
+0.20(1-p) \alpha_{\max }=1 \\
\alpha_{\max }=\frac{p}{1.32(1-p)} .
\end{aligned}
$$

To counteract the self-desiccation effect of concrete and mitigate the autogenous shrinkage of concrete, the volume of IC water shall be equal to the chemical shrinkage of concrete when the cement reaches the maximum hydration degree.

Introduce equation (11) into equation (3):

$$
V_{\text {iw }}=0.20(1-p) \alpha_{\max }=0.152 p,
$$

where $V_{\text {iw }}$ is the relative volume fraction $\left(\mathrm{m}^{3} / \mathrm{m}^{3}\right.$ cement paste) of IC water.

As a result,

$$
\begin{aligned}
V_{\mathrm{iw}} & =0.152 V_{\mathrm{cw}, 0}, \\
\left(\frac{w}{c}\right)_{i} & =0.152\left(\frac{w}{c}\right) .
\end{aligned}
$$

According to the Powers' model, the calculation formula of IC water is a subsection function. The boundary point can be determined as follows:

$$
\frac{w}{c}+\left(\frac{w}{c}\right)_{i} \leq 0.42 \longrightarrow \frac{w}{c}+0.152\left(\frac{w}{c}\right) \leq 0.42 \longrightarrow \frac{w}{c} \leq 0.36 .
$$

Hence, the calculation formula of IC water of concrete can be described in equation (16) and Figure 1.

$$
\begin{cases}\left(\frac{w}{c}\right)_{i}=0.152\left(\frac{w}{c}\right), & \frac{w}{c} \leq 0.36, \\ \frac{w}{c}+\left(\frac{w}{c}\right)_{i}=0.42, & 0.36<\frac{w}{c} \leq 0.42, \\ 0, & \frac{w}{c}>0.42 .\end{cases}
$$

2.2. Concrete with Mineral Admixture. In the concrete mixed with mineral admixture, it is assumed that the contents of chemical binding water and gel water of mineral admixture are the same as those of cement when hydrated completely. The modified hydration model of cementitious materials containing mineral admixture is as follows:

$$
\begin{aligned}
& V_{\mathrm{cs}}=\rho_{\mathrm{b}}\left(6.4 \times 10^{-5}+A_{\mathrm{m}} x\right)(1-p) \alpha \\
& V_{\mathrm{gw}}=0.19\left(\frac{\rho_{\mathrm{b}}}{\rho_{\mathrm{w}}}\right)(1-p) \alpha \\
& V_{\mathrm{gs}}=\left[1-\left(6.4 \times 10^{-5}+A_{\mathrm{m}} x\right) \rho_{\mathrm{b}}+0.23\left(\frac{\rho_{\mathrm{b}}}{\rho_{\mathrm{w}}}\right)\right](1-p) \alpha \\
& V_{\mathrm{uc}}=(1-p)(1-\alpha)
\end{aligned}
$$

where $\rho_{\mathrm{b}}$ is the density of cementitious materials, $\mathrm{kg} / \mathrm{m}^{3} ; \rho_{\mathrm{w}}$ is the density of water, $\mathrm{kg} / \mathrm{m}^{3} ; A_{\mathrm{m}}$ is influence coefficient of chemical shrinkage of mineral admixture, $\mathrm{m}^{3} / \mathrm{kg}$; and $x$ is the proportion of mineral admixture, $\%$.

As mentioned above, it is assumed that the hydration microstructure is completely occupied by four phases, namely, as gel solid, gel water, unhydrated cement particles, and chemical shrinkage, when the hydration degree of cement reaches the maximum. The expression of the maximum hydration degree of concrete with mineral admixture is shown in 


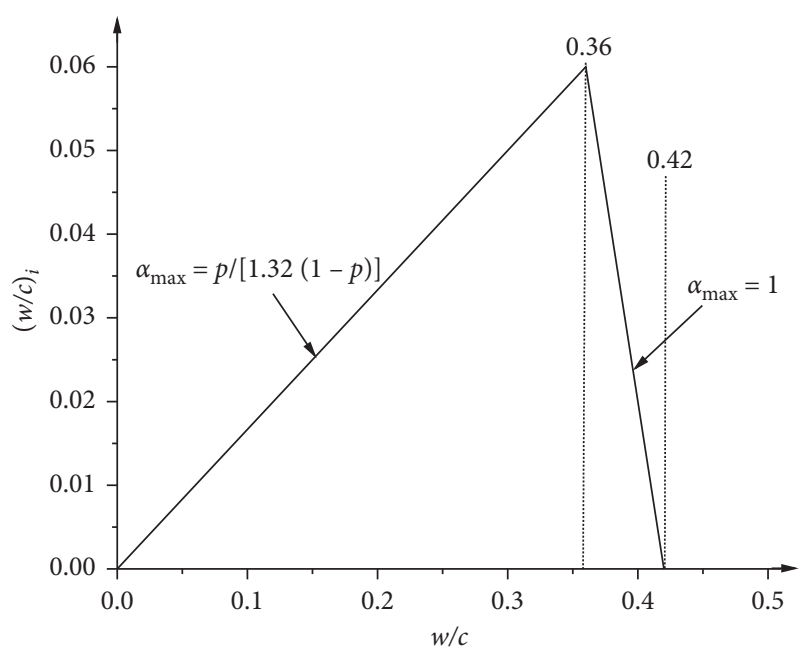

Figure 1: Minimum amount of IC water needed to obtain $\alpha_{\max }$ in cement pastes without mineral admixture.

$$
\begin{aligned}
& 0.19\left(\frac{\rho_{\mathrm{b}}}{\rho_{w}}\right)(1-p) \alpha_{\max } \\
& +\left[1-\left(6.4 \times 10^{-5}+A_{\mathrm{m}} x\right) \rho_{\mathrm{b}}+0.23\left(\frac{\rho_{\mathrm{b}}}{\rho_{w}}\right)\right](1-p) \alpha_{\max } \\
& \quad+(1-p)\left(1-\alpha_{\max }\right)+\rho_{\mathrm{b}}\left(6.4 \times 10^{-5}+A_{\mathrm{m}} x\right) \\
& \quad \cdot(1-p) \alpha_{\max }=1,
\end{aligned}
$$

$$
\alpha_{\max }=\frac{p}{0.42\left(\rho_{\mathrm{b}} / \rho_{\mathrm{w}}\right)(1-p)}
$$

Similar to the concrete without mineral admixture, the volume of IC water shall be equal to the chemical shrinkage of concrete with mineral admixture, when the hydration degree of cement reached to the maximum.

Introduce equation (22) into equation (17):

$$
\begin{aligned}
V_{\mathrm{iw}}= & \rho_{\mathrm{b}}\left(6.4 \times 10^{-5}+A_{\mathrm{m}} x\right)(1-p) \\
& \times \frac{p}{0.42\left(\rho_{\mathrm{b}} / \rho_{\mathrm{w}}\right)(1-p)}=\frac{\left(6.4 \times 10^{-5}+A_{m} x\right) p}{0.42}
\end{aligned}
$$

where $V_{\text {iw }}$ is the volume of IC water, $\mathrm{m}^{3}$.

As a result, the calculation method for IC water in the concrete with mineral admixture can be described as follows:

$$
\left(\frac{w}{b}\right)_{i}=\left(0.152+\frac{\rho_{w} A_{m} x}{0.42}\right)\left(\frac{w}{b}\right)
$$

According to the Powers' model, the calculation formula of IC water is a subsection function. The boundary point can be determined as follows:

$$
\begin{aligned}
\frac{w}{b}+\left(\frac{w}{b}\right)_{i} & \leq 0.42 \longrightarrow \frac{w}{b}+\left(0.152+\frac{\rho_{\mathrm{w}} A_{\mathrm{m}} x}{0.42}\right)\left(\frac{w}{b}\right) \\
& \leq 0.42 \longrightarrow \frac{w}{b} \leq \frac{0.42}{\left(1.152+\left(\rho_{\mathrm{w}} A_{\mathrm{m}} x / 0.42\right)\right) .}
\end{aligned}
$$

Hence, the calculation formula of IC water of concrete can be described in equation (26) and Figure 2.

$$
\left\{\begin{array}{l}
\left(\frac{w}{b}\right)_{i}=\left(0.152+\frac{\rho_{\mathrm{w}} A_{\mathrm{m}} x}{0.42}\right)\left(\frac{w}{b}\right) \\
\frac{w}{b}+\left(\frac{w}{b}\right)_{i}=0.42, \\
0
\end{array}\right.
$$

The effect of FA on the chemical shrinkage of hardened concrete has been studied [18]. The addition of FA can reduce the chemical shrinkage of hardened concrete and more with the dosage of FA between 0 and $30 \%$ by weight. The quantitative relation among the content of FA and chemical shrinkage can be established based on the chemical shrinkage at the age of 63 days. The result is a linear relation between chemical shrinkage and dosage of FA as shown in equation (27), and the influence coefficient of chemical shrinkage $\left(A_{\mathrm{m}}\right)$ of FA is -0.0383 .

$$
\begin{aligned}
& \frac{w}{b} \leq \frac{0.42}{\left(1.152+\left(\rho_{\mathrm{w}} A_{\mathrm{m}} x / 0.42\right)\right)} \\
& \frac{0.42}{\left(1.152+\left(\rho_{\mathrm{w}} A_{\mathrm{m}} x / 0.42\right)\right)}<\frac{w}{b} \leq 0.42, \\
& \frac{w}{b}>0.42 .
\end{aligned}
$$

$$
V_{\mathrm{cs}}=-0.0383 x_{\mathrm{FA}}+0.064 \text {, }
$$

where $x_{\mathrm{FA}}$ is the dosage of FA between 0 and $30 \%$ by weight, $\%$.

\section{Materials and Methods}

3.1. Materials. Reference cement was employed following China National Standard GB/T 8076-2008. The main performance indexes of this cement are provided in Table 1 . The 


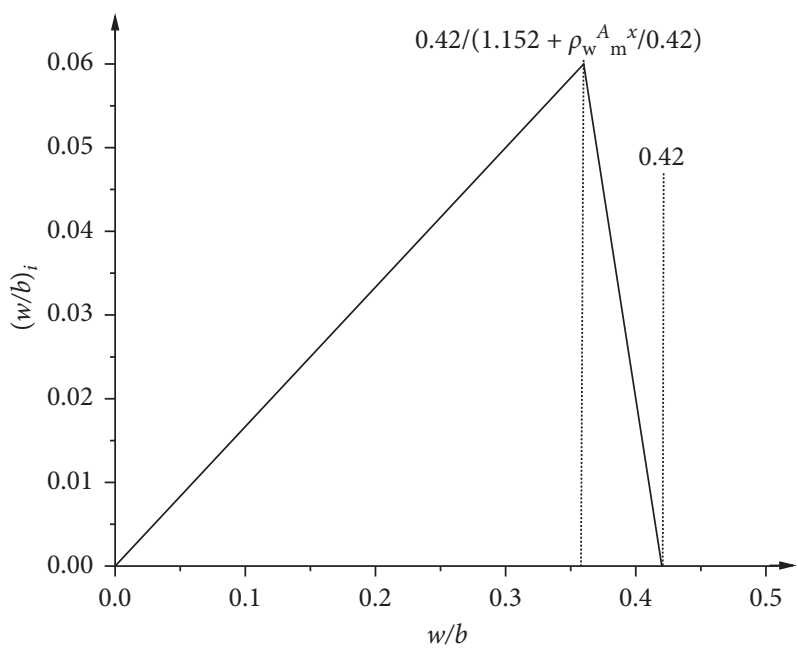

Figure 2: Minimum amount of IC water needed to obtain $\alpha_{\max }$ in cement pastes with mineral admixture.

TABLE 1: Main performance indexes of reference cement.

\begin{tabular}{|c|c|c|c|c|c|c|}
\hline \multirow[t]{2}{*}{$\rho_{\mathrm{c}}(\mathrm{kg} / \mathrm{L})$} & \multicolumn{2}{|c|}{ Setting time $(\min )$} & \multicolumn{2}{|c|}{ Flexural strength $(\mathrm{MPa})$} & \multicolumn{2}{|c|}{$\begin{array}{l}\text { Compressive strength } \\
(\mathrm{MPa})\end{array}$} \\
\hline & Initial & Final & $3 \mathrm{~d}$ & $28 \mathrm{~d}$ & $3 \mathrm{~d}$ & $28 \mathrm{~d}$ \\
\hline 3.15 & 155 & 215 & 5.5 & 8.6 & 28.3 & 49.8 \\
\hline
\end{tabular}

class I FA according to China National Standard GB/T 1596-2005 was used as a mineral admixture. The fine aggregate was natural river sand with a fineness modulus of 2.6 and an apparent density of $2.57 \mathrm{~kg} / \mathrm{L}$. The coarse aggregate used was crushed limestone with particle sizes between 5 and $20 \mathrm{~mm}$, bulk density of $1.61 \mathrm{~kg} / \mathrm{L}$, and apparent density of $2.83 \mathrm{~kg} / \mathrm{L}$. A liquid polycarboxylate-based superplasticizer was utilized to adjust the workability of different mixtures. Tap water was used for mixing concrete.

The SAP used in mixtures is a group of polymeric materials that could absorb a significant amount of liquid from the surroundings and retain this liquid within their structures without dissolution. Specifically, this study employed a suspension-polymerized, covalently crosslinked acrylamide/acrylic acid copolymer as SAP with a dry-bulk density of $1.031 \mathrm{~kg} / \mathrm{L}$. The particle size distributions of SAP (Figure 3) are determined by laser diffraction (wet diffusion method, the solvent is ethanol), and the value of the $D_{90}$ diameter of SAP particle size distribution is $130.02 \mu \mathrm{m}$. The absorption capacity of SAP was tested by the "tea-bag" method in this study, and the liquid came from the cement pastes with $w / c=0.33$. The cement pastes were mixed in a $2.5 \mathrm{~L}$ stirring mixer for $4 \mathrm{~min}$ at $150 \mathrm{rpm}$. After 20 minutes, the pastes were filled into the medium-speed centrifuge and rotated at $6000 \mathrm{rpm}$ for 20 minutes. Then, the upper solution of the pastes was filled into the high-speed centrifuge and rotated at $15000 \mathrm{rpm}$ for 30 minutes. Thereafter, the upper solution in the high-speed centrifugal tube was filtered by using a $0.45 \mu \mathrm{m}$ syringe filter, which was used by the water absorption test. The water absorption ratio of SAP is 29.8 .

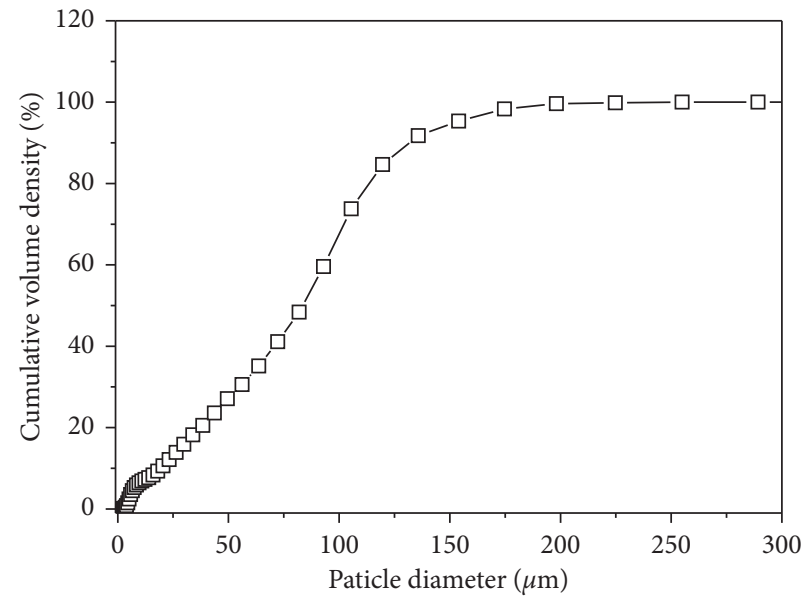

FIgURE 3: Cumulative particle size distribution of SAP.

3.2. Mixture Proportions. Six mix proportions of concrete were prepared and are listed in Table 2, whose compressive strength is designed not lower than $60 \mathrm{MPa}$ in 28 days. Mix $\mathrm{A} 0$ and $\mathrm{B} 0$ are references without SAP and IC water, while $\mathrm{A} 1, \mathrm{~A} 2, \mathrm{~B} 1$, and B2 are designed according to the method developed in this paper (As Sections 2.1 and 2.2) or equation (1), respectively.

\subsection{Testing Methods}

3.3.1. Autogenous Shrinkage. In this study, the autogenous shrinkage of concrete was tested using a combination of 
TABLE 2: Concrete mix proportions.

\begin{tabular}{|c|c|c|c|c|c|c|}
\hline Mixture & A0 & A1 & A2 & B0 & B1 & $\mathrm{B} 2$ \\
\hline Cement $\left(\mathrm{kg} / \mathrm{m}^{3}\right)$ & 503 & 503 & 503 & 395 & 395 & 395 \\
\hline $\mathrm{FA}\left(\mathrm{kg} / \mathrm{m}^{3}\right)$ & 0 & 0 & 0 & 123 & 123 & 123 \\
\hline Fine aggregate $\left(\mathrm{kg} / \mathrm{m}^{3}\right)$ & 656 & 656 & 656 & 642 & 642 & 642 \\
\hline Coarse aggregate $\left(\mathrm{kg} / \mathrm{m}^{3}\right)$ & 1084 & 1084 & 1084 & 1132 & 1132 & 1132 \\
\hline Water $\left(\mathrm{kg} / \mathrm{m}^{3}\right)$ & 166.4 & 166.4 & 166.4 & 150.1 & 150.1 & 150.1 \\
\hline Inter curing water $\left(\mathrm{kg} / \mathrm{m}^{3}\right)$ & 0 & 25.3 & 30.0 & 0 & 19.6 & 26.7 \\
\hline $\operatorname{SAP}\left(\mathrm{g} / \mathrm{m}^{3}\right)^{0}$ & 0 & 849.0 & 1006.7 & 0 & 657.7 & 896.0 \\
\hline Method & No & Equation (16) & Equation (1) & No & Equation (26) & Equation (1) \\
\hline
\end{tabular}

noncontact and contact methods successively, and the initial setting time was tested under the same conditions.

Noncontact sensors' measurement was monitored using the method prescribed in China National Standard GB/T 50082-2009 from the initial setting time to 48 hours. The sizes of concrete prism for the noncontact test were $100 \times 100 \times 515 \mathrm{~mm}$. A double-layer plastic film was laid in the steel mold, and the fresh concrete was cast in the room whose relative humidity was not less than $95 \%$ and temperature was $(20 \pm 2)^{\circ} \mathrm{C}$. Then, the remaining part of the same film was turned over to cover the top surface of the prism. The test target needed to pass through the plastic film, but the edge of the perforation needed to be sealed with petroleum jelly to ensure no water loss. The autogenous shrinkage test took the initial setting time of fresh concrete as the starting time, and the result was the arithmetic average of 3 test values. From the starting time to the end of the noncontact test, the laboratory had relative humidity $(65 \pm 5) \%$ and temperature $(20 \pm 2)^{\circ} \mathrm{C}$.

From 48 hours to 56 days, the autogenous shrinkage was measured using contact sensors, which was also adopted by China National Standard GB/T 50082-2009. The sizes of concrete prism and conditions in the casting room were the same as the noncontact test. The concrete cast within the mold was sealed with a double-layer plastic film to prevent water loss during the plastic stage. After standard curing for 24 hours, the hardened concrete prisms were taken from the molds, and then wrapped with an aluminum foil waterproof coil immediately. The starting time of the contact test was the end of the noncontact one. From the starting time to the end of the contact test, the relative humidity and temperature in the laboratory were the same as the noncontact. The result was the arithmetic average of 3 test values.

$$
\varepsilon_{\mathrm{a}}=\varepsilon_{\mathrm{a} 1}+\varepsilon_{\mathrm{a} 2},
$$

where $\varepsilon_{\mathrm{a}}$ is the autogenous shrinkage value, $\mu \varepsilon ; \varepsilon_{\mathrm{al}}$ is the autogenous shrinkage value of the noncontact test, $\mu \varepsilon ; \varepsilon_{\mathrm{a} 2}$ is the autogenous shrinkage value of contact test, $\mu \varepsilon$.

The calculation for autogenous shrinkage can be described as follows:

3.3.2. Internal Relative Humidity (IRH). Figure 4 shows the plastic molds utilized for testing IRH with net inner dimensions of $100 \times 100 \times 100 \mathrm{~mm}$ in the present study, as reported in [23-25]. The IRH in specimens sealed and cured condition was the same as those used in the autogenous shrinkage test.

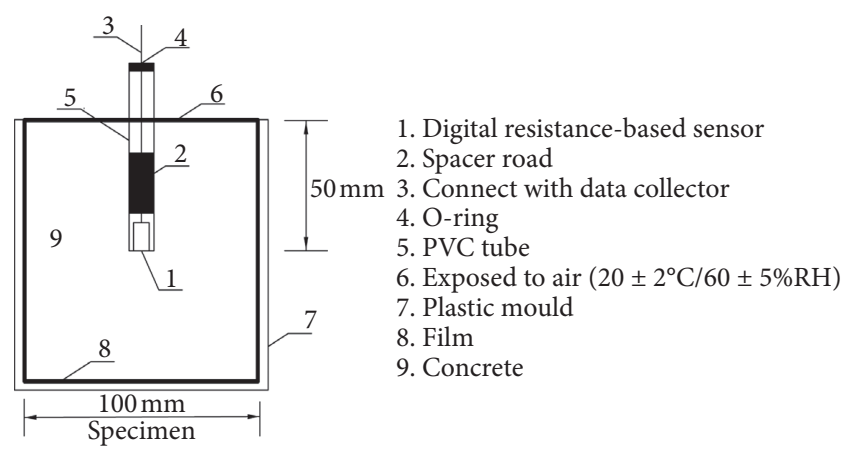

FIgURE 4: Specimen size and arrangements of the sensors in specimen [22].

IRH in concrete was measured with a digital resistance-based sensor. A computer was utilized to record the sensor signals automatically. To hold the sensor in the specimen and to avoid fresh concrete contaminating the sensor, a polyvinyl chloride (PVC) tube with an inner diameter of $16 \mathrm{~mm}$ was utilized in the experiments, as shown in Figure 4. To prevent fresh concrete from flowing into the PVC tube, an aluminum bar was first inserted into the PVC tube during concrete casting [22]. Following the final setting time, the aluminum bar was replaced with the $\mathrm{RH}$ sensor. An O-ring was utilized to isolate the small space between the PVC tube and the sensor to facilitate accurate measurement. To avoid environmental disturbance, the exposed end of the PVC tube was sealed with an epoxy resin sealant.

The positions of the sensors and the PVC tubes in the specimens are shown in Figure 4. All specimens were tested at a climate room $\left((20 \pm 2)^{\circ} \mathrm{C},(60 \pm 5) \% \mathrm{RH}\right)$. IRH variations in three identical samples were measured simultaneously, and the arithmetic mean value was utilized for analysis and discussion.

3.3.3. Compressive Strength. Compressive strength tests were carried out after 3, 7, 28, and 56 days, according to China National standard GB/T 50081-2002. The specimen cubes with the size of $150 \mathrm{~mm} \times 150 \mathrm{~mm} \times 150 \mathrm{~mm}$ were used in tests.

3.3.4. Content of Nonevaporable Water [26]. The nonevaporable water content was measured to quantify the hydration degree of cement and a larger content indicated a 
higher hydration degree. The samples were mixed according to Table 2 but by getting rid of sand and stone. At 3,28 , and 56 days, the samples were soaked in an acetone bath for $48 \mathrm{~h}$ to terminate hydration, respectively. Afterward, the samples were dried at $105^{\circ} \mathrm{C}$ for $24 \mathrm{~h}$ to get rid of the capillary and gel water. Subsequently, the dried samples were dehydrated in a muffle furnace at $1000^{\circ} \mathrm{C}$ until the weight remained unchanged. Finally, the chemically bound water content was calculated according to the mass loss from $105^{\circ} \mathrm{C}$ to $1000^{\circ} \mathrm{C}$. Six samples for each mixture at the selected age were measured simultaneously, and the result was an arithmetic mean value.

3.3.5. Content of Calcium Hydroxide. The content of calcium hydroxide in harden cement pastes was tested by TGDTA, according to ASTM E1131-08. The sample preparation was consistent with that of the nonevaporable water experiment. The equipment used was the simultaneous TGDTA/DSC apparatus with a balance accurate to $0.1 \mu \mathrm{g}$. The dynamic heating ramp varied between $40^{\circ} \mathrm{C}$ and $1200^{\circ} \mathrm{C}$, and the heating rate was $10^{\circ} \mathrm{C} / \mathrm{min}$. The crucibles used were made of special ceramic. The test process was conducted under a $\mathrm{N}_{2}$ atmosphere. Approximately $100 \mathrm{mg}$ of the sample was used for each test.

3.3.6. Pore Structure in Harden Paste. The pore structure of hardened pastes was determined by using mercury intrusion porosimetry (MIP) prescribed in ISO 15901-1-2016. The sample preparation was consistent with that of the nonevaporable water experiment. After being cured for 56 days, the harden pastes were cut into small pieces of diameter about $5 \mathrm{~mm}$, and then placed into an alcohol bath (analytical grade) to stop cement hydration. The resulting samples were stored for 3 days in an oven at a controlled temperature of $(50 \pm 2)^{\circ} \mathrm{C}$, before the MIP test to determine the pore structure characteristics using a Hg-porosimetry. In this study, the range of the micropore size was from $3 \mathrm{~nm}$ to $5000 \mathrm{~nm}$ tested by MIP.

\subsubsection{Air Void Characteristics in Hardened Concrete.} The air-void content of hardened concrete was determined by microscopic examination at the age of 56 days, complying with ASTM C457-16 (linear-traverse method) [27]. The inspected surface of the slice sample was treated by grinding, polishing, water cleaning and oven drying. To enhance the contrast of the image, black ink was painted to the surface as the background. Barium sulfate powder was then gently pressed into open voids and the exterior residues were scraped out [28]. Thereby, the air content was identified by the RapidAir system [29]. The average air content of three samples from one prism was obtained as the final value for every hardened concrete. In this study, the air void was from $5000 \mathrm{~nm}$ to $4000 \mu \mathrm{m}$ measured by image analysis.

\section{Results and Discussion}

4.1. Autogenous Shrinkage. It has often been reported that the addition of SAP in concrete led to a reduction of autogenous shrinkage in comparison with reference concrete [11-13]. The results obtained in this study, as shown in Figure 5, were in good agreement with the observations reported in the literature. As seen in Figure 5, the increase in autogenous shrinkage in all concrete before 10 days was more significant than that from 10 days to 56 days, which may be due to a higher hydration rate in the early age concrete.

Compared to the reference concrete without FA (A0), the autogenous shrinkage of A1 and A2 had the same reduction, which by $53.7 \%, 50.2 \%$ at 28 days, and by $44.2 \%$, $41.3 \%$ at 56 days, as shown Figure 5(a). The reason of the above results was that there was little difference in the dosage of SAP and entrainment of IC water between A1 and A2 (See Table 2). By comparing autogenous shrinkage between A0 and B0, it was found that FA could reduce autogenous shrinkage of concrete, which was in agreement with works of literature. In this study, autogenous shrinkage of B0 reduced by $13.8 \%$ compared to A0.

As shown in Figure 5(b), the evolutions of autogenous shrinkage of $\mathrm{B} 1$ and $\mathrm{B} 2$ were similar, and the values reduced by $35.3 \%, 35.5 \%$ at 28 days and $48.0 \%$ and $48.1 \%$ at 56 days, respectively. The amount of IC water in B2 was calculated according to equation (1), in which the effect of FA on hydration was not considered. The IC water mixed in B2 was higher than that needed for maximum hydration degree of cement and FA in B2, and the excess IC water had little effect on the autogenous shrinkage reduction.

4.2. IRH. Autogenous shrinkage occurs as a result of both an increase in the capillary pore pressure with water consumed in the hydration process and relative humidity decreases in cementitious materials. Therefore, the autogenous shrinkage is highly related to the evolution of IRH inside the concrete. The swelling SAP would release absorbed water gradually when the IRH inside concrete is reduced due to the hydration of binder materials.

The relationship between IRH and the age of the six concrete mixtures was studied and shown in Figure 6. It appeared that the addition of SAP and IC water significantly increased the IRH inside concrete with or without FA.

Meanwhile, the IRH inside the concrete without FA (A0) was decreased rapidly before 10 days and slowly from 10 days to 56 days, and the evolution was similar to its autogenous shrinkage (As shown in Section 4.1). With FA introduced into the concrete (B0), deriving from the filling effect of FA inhibited the transition of water and the FA had a lower reactivity than cement, and the decreasing rate of humidity was reduced. As a result, the IRH inside concrete with FA (B0) showed a slow decline compared to that without FA (A0). The IRH of A0, A1, A2 were reduced by $22.2 \%, 15.0 \%, 13.7 \%$ at 28 days and by $23.4 \%, 16.1 \%, 15.2 \%$ 

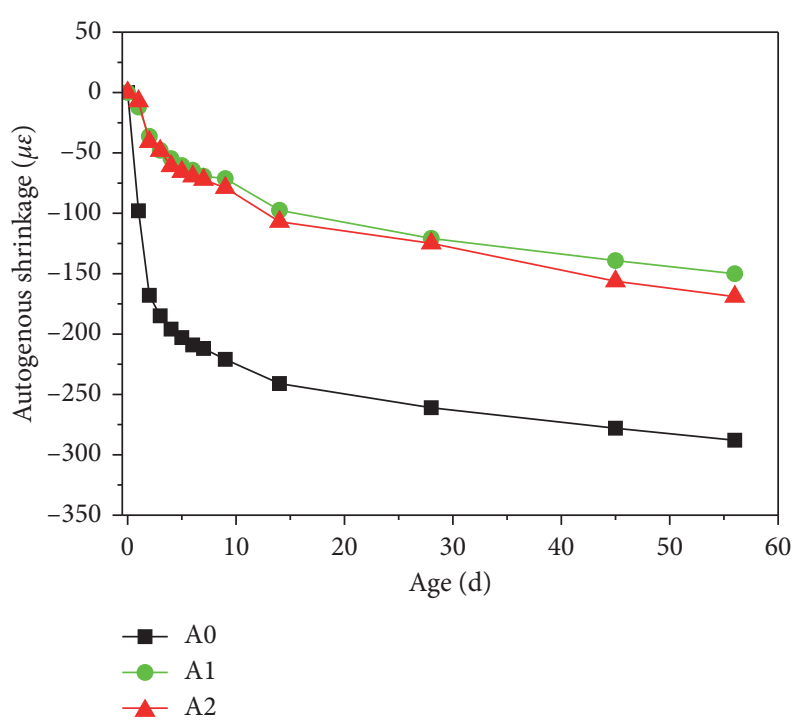

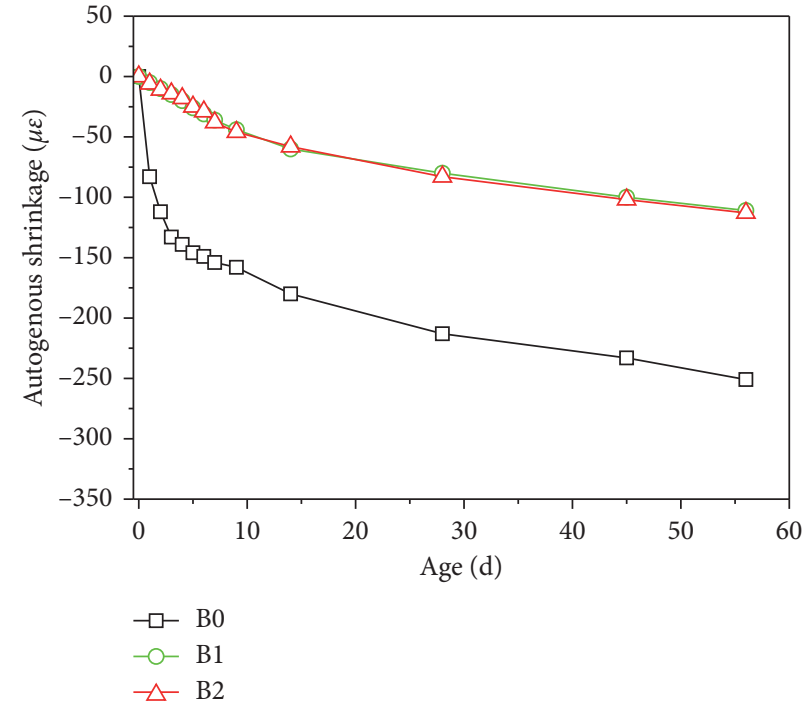

(b)

FIGURE 5: Relationship between autogenous shrinkage and age of concrete. (a) Concrete without FA; (b) concrete with FA.

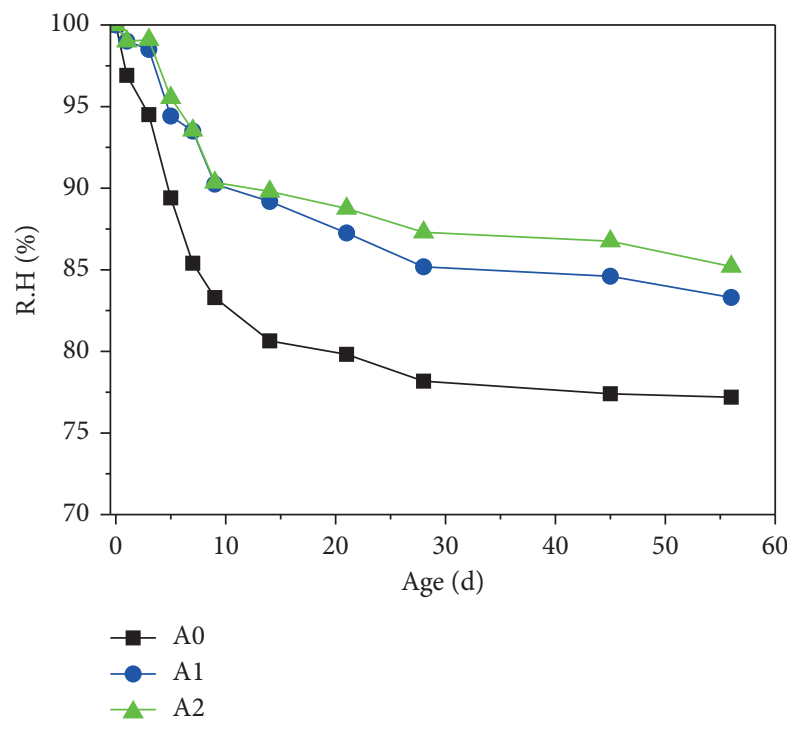

(a)

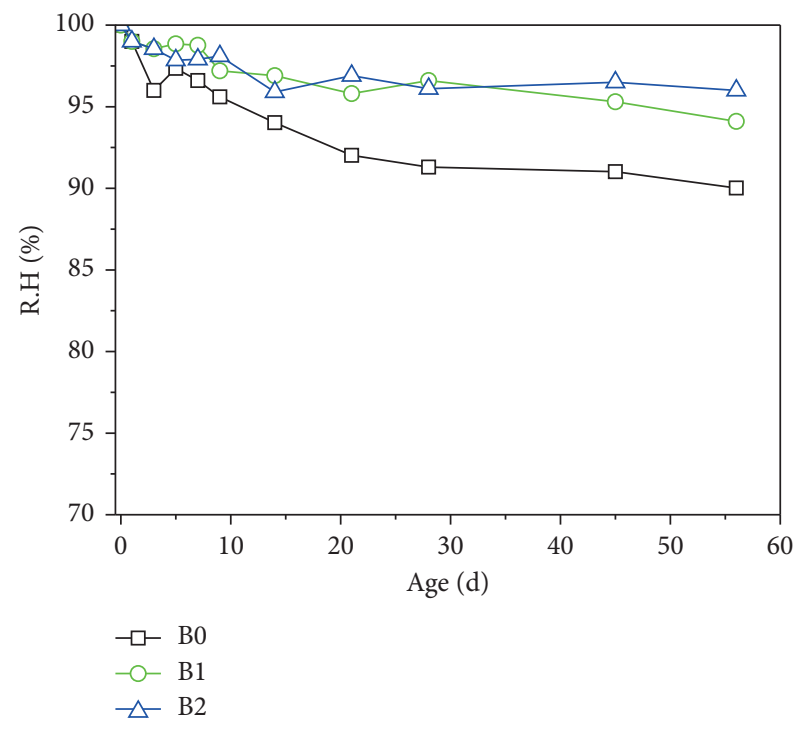

(b)

FIgURE 6: Relationship between IRH and age of concrete. (a) Concrete without FA; (b) concrete with FA.

at 56 days. While the B0, B1, B2 were reduced by $8.5 \%, 3.4 \%$, $3.8 \%$ at 28 days and by $10.2 \%, 5.8 \%, 4.6 \%$ at 56 days.

As compared between $\mathrm{A} 1$ and $\mathrm{A} 2$, or between $\mathrm{B} 1$ and $\mathrm{B} 2$, the IRH showed nearly the same evolution in the concrete with or without FA, which could explain the effect of the IC with SAP on the autogenous shrinkage of concrete in Section 4.1.

4.3. Compressive Strength. The addition of SAP and IC water constituted the compressive strength of concrete compared to reference concrete reduced in some previous studies
$[4,14]$. The results obtained in this study are shown in Figure 7, which were consistent with those of previous studies. However, by accurately calculating the amount of SAP and IC water, the problem was significantly improved, especially for concrete with FA.

As seen in Figure 7, the compressive strength of concretes with SAP (A1 and A2) were lower than that without SAP from 3 days to 56 days, but the gap was getting smaller and smaller with the increasing of the age. Compared to A0, the compressive strengths of $\mathrm{A} 1$ and $\mathrm{A} 2$ were decreased by $12.1 \%$ and $13.0 \%$ at 3 days, while by $1.2 \%$ and $1.7 \%$ at 56 days. There was little difference in compressive strength 


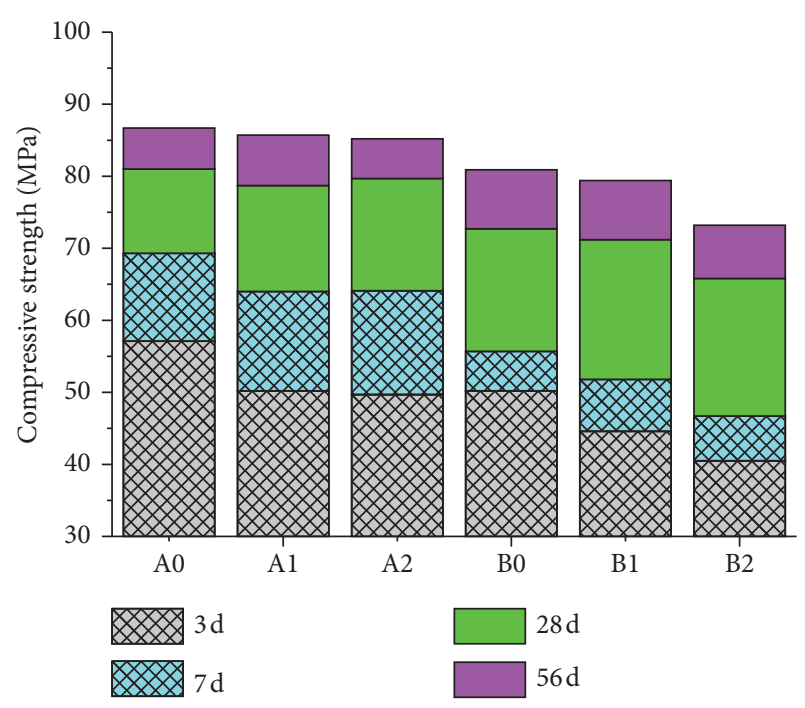

FIGURE 7: Relationship between compressive strength and age of concrete. (A) Concrete without FA; (B) concrete with FA.

between $\mathrm{A} 1$ and $\mathrm{A} 2$ from 3 days to 56 days, as shown in Figure 7. This meant that the difference between equation (16) proposed by this study and equation (1) presented by Jenson had no obvious effect on the compressive strength of concrete without FA.

In contrast to concrete without $\mathrm{FA}$, the compressive strength of concretes with SAP (B1 and B2) were also lower than that without SAP (B0) from 3 days to 56 days, and the gap of both B1 and B2 got smaller with the age getting on as well. However, this improvement of B1 was very similar to A1, while B2 was not as good as A2, as shown in Figure 7. As compared to B0, the compressive strengths of B1 and B2 were reduced by $11.2 \%$ and $19.3 \%$ at 3 days, while by $1.9 \%$ and $9.5 \%$ at 56 days. The difference between equation (26) proposed by this study and equation (1) proposed by Jenson affected the compressive strength of concrete with FA. That meant the IC water and SAP calculated by this new method was more accurate than the one without the mineral admixture considered, which was able to reduce the excessive IC water and SAP dosage. The higher dosage of SAP and the more entrainment of IC water would reduce the compressive strength.

Concrete is a kind of porous material, and its compressive strength is determined by the pore structure and the hydration degree of the harden concrete. The effects of SAP on the pore structure and degree of hydration of the harden concrete must be discussed below.

4.4. Degree of Hydration. Nonevaporable water content and calcium hydroxide content are commonly used to evaluate the degree of hydration in cementitious materials [30,31]. The nonevaporable water content and calcium hydroxide content of the hardened cement paste at 3,28, and 56 days are shown in Figures 8 and 9. Whether cement with or without FA, the effects of the internal curing using SAP on the nonevaporable water content and calcium hydroxide content of cement pastes were very similar.

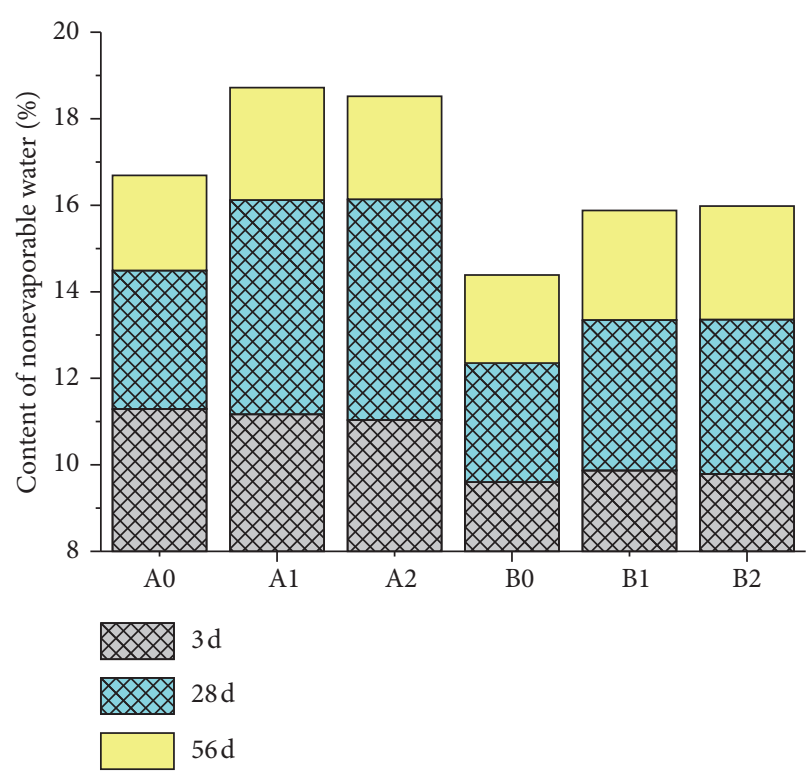

FIGURE 8: Effect of IC with SAP on nonevaporable water in harden cement pastes. (A) Cement pastes without FA; (B) cement pastes with FA.

SAP had a little effect on the nonevaporable water content in cement pastes with or without FA at 3 days, while showed a noticeable increase at 28 days and 56 days, compared to the reference one with or without FA. As shown in Figure 8, compared with the reference specimen without FA (A0), the nonevaporable water content in A1 and $\mathrm{A} 2$ were increased by $-1.1 \%$ and $-2.2 \%$ at 3 days, by $11.2 \%$ and $11.4 \%$ at 28 days, and then by $12.2 \%$ and $11.0 \%$ at 56 days, respectively. To the paste with FA (B0), the nonevaporable water content in B1 and B2 were increased by $2.8 \%, 2.0 \%$ at 3 days, by $8.1 \%, 8.2 \%$ at 28 days, and then by $10.4 \%, 11.1 \%$, respectively.

Similar to nonevaporable water content, SAP had a little effect on the calcium hydroxide content in cement pastes with or without FA at 3 days, with an obvious increase at 28 days and 56 days. As indicated in Figure 9, compared with the reference specimen without FA (B0), the calcium hydroxide content in A1 and A2 were increased by $2.2 \%$ and $2.2 \%$ at 3 days, by $15.4 \%$ and $15.3 \%$ at 28 days, and then by $4.5 \%$ and $4.4 \%$ at 56 days, respectively. To the paste with FA (B0), the calcium hydroxide content in B1 and B2 were increased by $2.7 \%,-0.5 \%$ at 3 days, by $6.5 \%, 6.1 \%$ at 28 days, and then by $14.2 \%, 15.1 \%$ respectively.

The SAP and IC water had increased the degree of hydration of cementitious materials at 28 days and 56 days, which was in agreement with some previous reports [32,33], benefiting from the $\mathrm{RH}$ inside the specimens increasing (Section 4.2).

The paste designed equations (26) or (1) had nearly the same hydration degree from 3 days to 56 days. Therefore, the excess IC water and SAP calculated by equation (1) without mineral admixture considered had no significant benefit to the hydration degree of cementitious materials. 


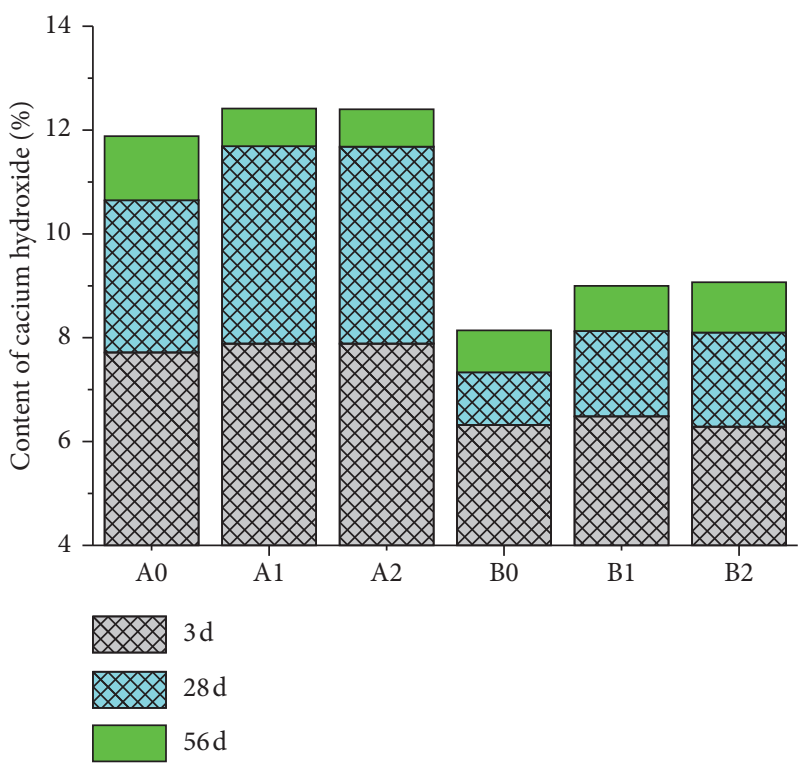

FIGURE 9: Effect of IC with SAP on calcium hydroxide in harden cement pastes. (A) Cement pastes without FA; (B) cement pastes with FA.

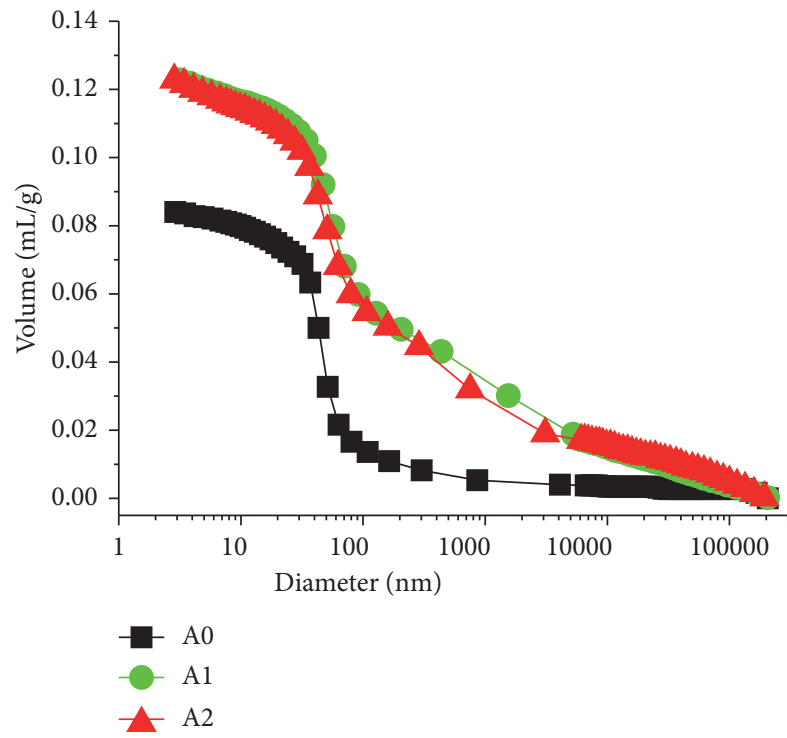

(a)

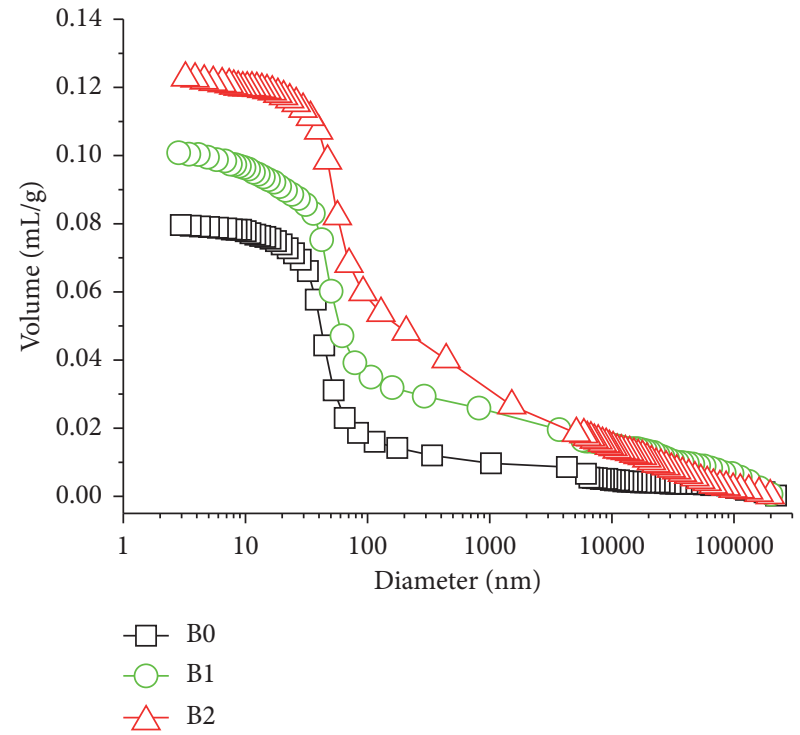

(b)

Figure 10: Effects of SAP on pore structure (cumulative pore size distribution) in the hardened cement pastes at the age of 56 days determined by MIP. (a) Harden pastes without FA; (b) harden pastes with FA.

In theory, the higher hydration degree is, and the compressive strength of concrete is higher, but IC with SAP was not (Section 4.3). Then the effect of SAP and IC water on the pore structure of hardened concrete should be emphasized.

4.5. Pore Structure in Hardened Paste. There is a wide range of pore size distribution in hardened concrete by lots of researches, and the pores in a certain size range can have different effects on hardened concrete.
In this paper, the range of pore size from $3 \mathrm{~nm}$ to $10000 \mathrm{~nm}$ in hardened concrete was named as the micropore (mainly capillary pores), while the range from $10000 \mathrm{~nm}$ to $4000 \mu \mathrm{m}$ as the macropore (all air voids). The micropore structure was tested by MIP, which is the most popular method for characterizing the micropore structure of hardened cementitious materials $[34,35]$. And the macropore structure was measured by image analysis.

In both micropore and macropore, the pore size smaller than $20 \mathrm{~nm}, 20-50 \mathrm{~nm}, 50-200 \mathrm{~nm}$ and larger than $200 \mathrm{~nm}$ could be named as harmless, less harmful, harmful, and 


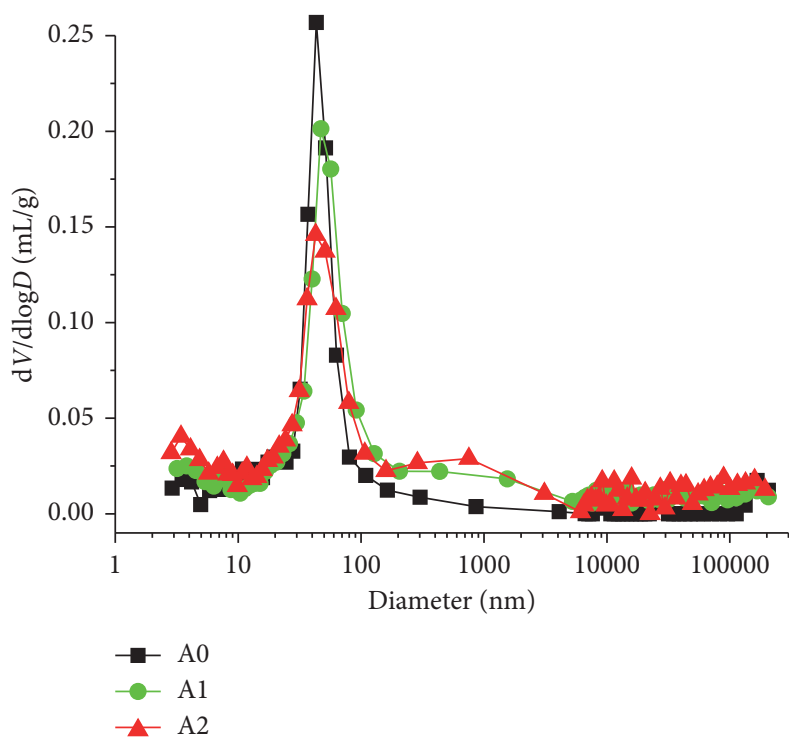

(a)

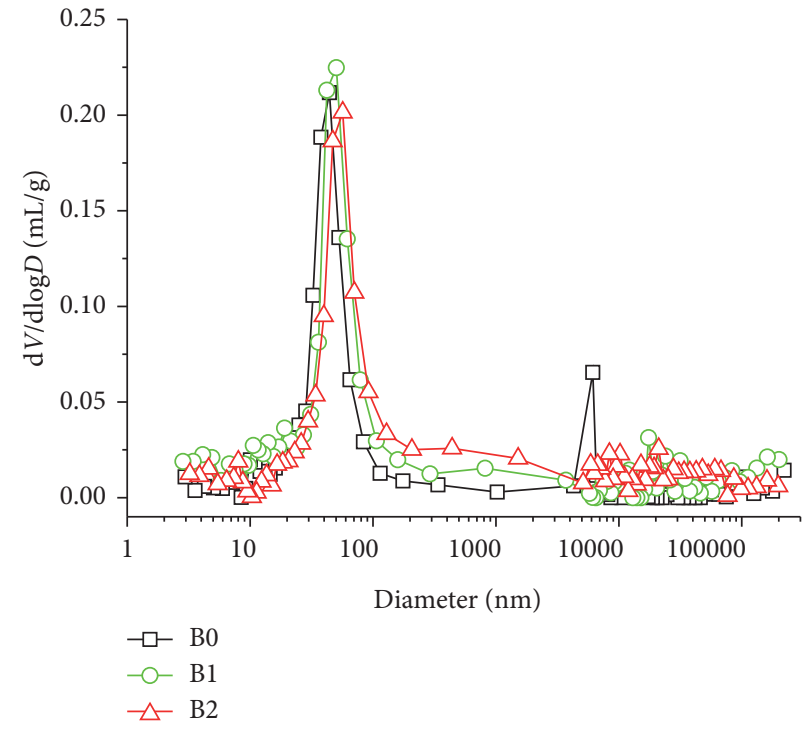

(b)

Figure 11: Effects of SAP on pore structure (differential pore size distribution) in the hardened cement pastes at the age of 56 days determined by MIP. (a) Hardened pastes without FA; (b) hardened pastes with FA.

TABLE 3: Results of pore structure in hardened pastes.

\begin{tabular}{lcccc}
\hline Samples & Total pore volume $(\mathrm{mL} / \mathrm{g})$ & \multicolumn{2}{c}{ Pores size distribution $(\mathrm{mL} / \mathrm{g})$} \\
& & $<20 \mathrm{~nm}$ & $20-50 \mathrm{~nm}$ & $50-200 \mathrm{~nm}$ \\
\hline A0 & 0.0840 & 0.0094 & 0.0388 & 0.0256 \\
A1 & 0.1228 & 0.0104 & 0.0241 & 0.0384 \\
A2 & 0.1228 & 0.0137 & 0.0293 & 0.0313 \\
B0 & 0.0796 & 0.0058 & 0.0385 & 0.0214 \\
B1 & 0.1003 & 0.0099 & 0.0297 & 0.0359 \\
B2 & 0.1228 & 0.0053 & 0.0240 & 0.0499 \\
\hline
\end{tabular}

more harmful pores, respectively. The harmless and less harmful pores affect shrinkage and creep, while having no significant effect on strength [36, 37]. The strength was mainly dependent on the harmful and more harmful pores.

The effect of SAP on the micropore structure was investigated and is shown in Figures 10 and 11 and Table 3. It was seen that the addition of SAP and IC water certainly increased the total pore volume and pore volume larger than $50 \mathrm{~nm}$ in hardened paste, compared with the reference specimens with or without FA (A0 and B0). For concrete without FA, the total, harmful, and more harmful pore volume in A1 was increased by $46.2 \%, 50.0 \%$, and $389.2 \%$, respectively, while by $46.2 \%, 22.3 \%$, and $375.5 \%$ in $\mathrm{A} 2$, as shown in Figures 10(a), 11(a) and Table 3. And for concrete with $\mathrm{FA}$, those values in B1 were increased by $26.0 \%, 67.8 \%$, and $78.4 \%$, while by $54.3 \%, 109.3 \%$, and $250.4 \%$, as shown in Figures 10(b) and 11(b) and Table 3. This was one of the reasons why the compressive strength of concrete with SAP was still reduced despite the increase in hydration.

There were also significant differences in the total pore volume and the size distribution of micropores in the hardened paste with FA when the concrete mixtures were calculated from equations (1) and (26). As shown in
Figures 10(a) and 11(a) and Table 3, all the pore volumes were similar between $\mathrm{A} 1$ and $\mathrm{A} 2$ because the dosage of both SAP and IC water was nearly the same. However, as shown in Figures 10(b) and 11(b) and Table 3, not only the total pore volume, but also the harmful and more harmful pore volumes in $\mathrm{B} 2$ were more than $\mathrm{B} 1$, which were caused by the greater dosage of both SAP and IC water. This was one of the reasons why the compressive strength reduction of $\mathrm{B} 1$ was less than B2, and equation (26) was more accurate for the internal curing concrete with FA than equation (1). Kong et al. [1] thought that the addition of SAP affected pore distribution, because of the extra IC water entrained by SAP and formation of large voids due to the drying of SAP gel particles.

4.6. Air Void Characteristic in Hardened Concrete. The air void characteristics in hardened concrete with and without FA are shown in Figure 12 and Table 4. As compared to reference samples with or without FA (A0 and B0), the air contents were increased and the spacing factors were decreased obviously when SAP was mixed in concrete. For concrete without FA (A0), the air contents in A1 and A2 


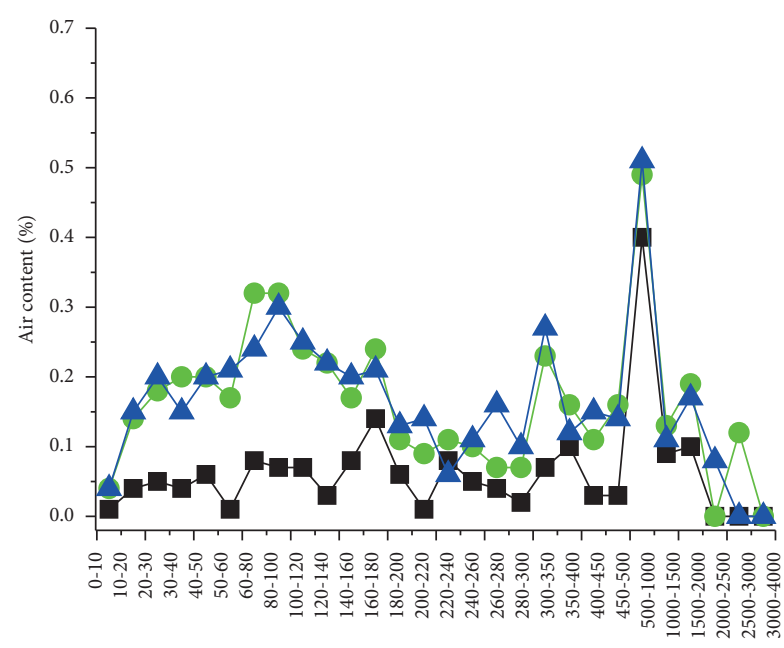

Diameter $(\mu \mathrm{m})$

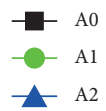

(a)

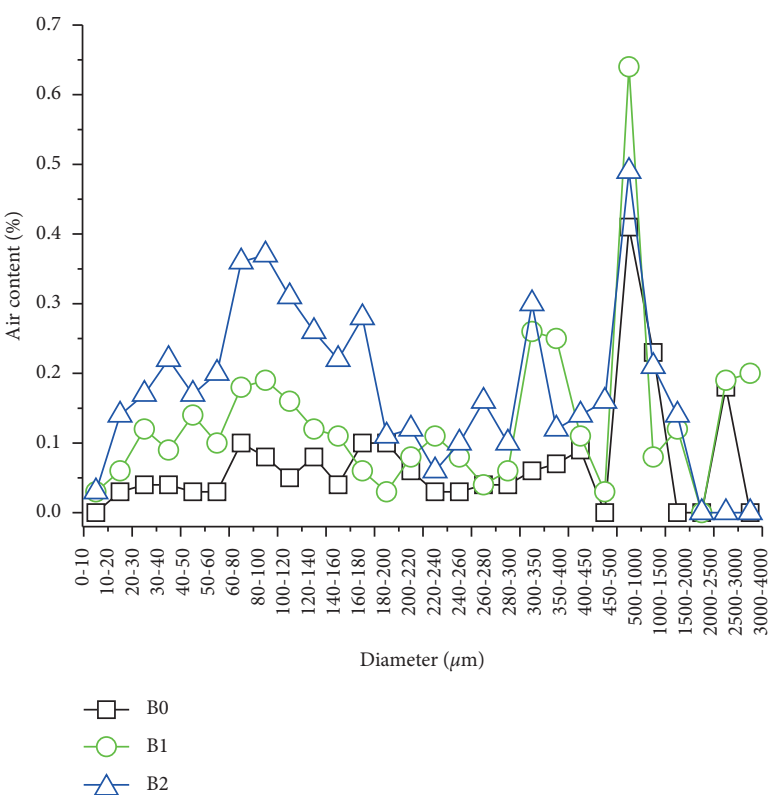

(b)

FIgURE 12: Air void distributions in harden concrete. (a) Concrete without FA; (b) concrete with FA.

TABLE 4: Results of air void characteristic in harden concrete.

\begin{tabular}{|c|c|c|c|c|c|}
\hline \multirow{2}{*}{ Samples } & \multirow{2}{*}{ Air content $(\%)$} & \multirow{2}{*}{ Spacing factor $(\mu \mathrm{m})$} & \multicolumn{3}{|c|}{ Air void distributions (\%) } \\
\hline & & & $0-200 \mu \mathrm{m}$ & $200-1000 \mu \mathrm{m}$ & $1000-4000 \mu \mathrm{m}$ \\
\hline A0 & 1.76 & 249 & 0.74 & 0.83 & 0.19 \\
\hline A1 & 4.58 & 137 & 2.55 & 1.59 & 0.44 \\
\hline $\mathrm{A} 2$ & 4.62 & 135 & 2.50 & 1.76 & 0.36 \\
\hline B0 & 1.96 & 295 & 0.72 & 0.83 & 0.41 \\
\hline B1 & 3.64 & 180 & 1.39 & 1.66 & 0.59 \\
\hline B2 & 4.94 & 140 & 2.84 & 1.75 & 0.35 \\
\hline
\end{tabular}

were increased by $160.2 \%$ and $162.5 \%$, and the spacing factor was decreased by $45.0 \%$ and $45.8 \%$, respectively. For concrete with $\mathrm{FA}(\mathrm{B} 0)$, the air contents in $\mathrm{B} 1$ and $\mathrm{B} 2$ were increased by $85.7 \%$ and $152.0 \%$, and the spacing factor was decreased by $39.0 \%$ and $52.5 \%$, respectively. Furthermore, the size of air voids in the range of less than $200 \mu \mathrm{m}$ was increased substantially; in the range of $200-1000 \mu \mathrm{m}$, was increased slightly; and in the range of $1000-4000 \mu \mathrm{m}$ there was no significant growth. After the IC water had been released from SAP, the SAP would leave a hole in situ. Therefore, these values meant that the number of air voids was increased due to the addition of SAP in concrete, which was another reason why the compressive strength of concrete with SAP was still reduced despite the increase in hydration.

Besides the pore structure in the hardened paste, the differences in the content, spacing factor, and size distribution of air voids in concrete with FA were significant, when the concrete mixtures were calculated from equations (1) and (26). As shown in Figure 12(a) and Table 4, the content, spacing factor, and distribution of air voids were very close between A1 and A2, duo to nearly the same dosage of SAP. However, as shown in Figure 12(b) and Table 4, the air content and air voids less than $200 \mu \mathrm{m}$ in B2 were higher than B1 obviously, and the spacing factor of air voids in B2 was less than B1, which had come from the higher dosage of SAP. This was another reason why the compressive strength reduction of B1 was less than B2, and then the equation (26) was more accurate for the internal curing concrete with FA than equation (1).

\section{Conclusion}

This study focused on a developed method for IC water calculation of concrete with SAP, and its benefits for the macro performance and microstructure of hardened concrete with and without mineral admixture were evaluated. The following conclusions can be drawn based on the obtained results:

(1) Deriving from the Powers' model for the phase distribution of a hydrating cement paste, a developed method for calculating IC water of concrete with and without mineral admixture is proposed, which takes into account the effects of chemical shrinkage and mineral admixture compared with the method proposed previously. 
(2) For the mix designs without FA, the autogenous shrinkage and the compressive strength of hardened concrete were similar, due to the little difference in the entrainment of IC water and the dosage of SAP calculated between the methods proposed in this paper and the one reported previously (See equation (1)).

(3) For the mix designs with FA, the entrainment of IC water and the dosage of SAP calculated by the method proposed in this paper decreased by $26.6 \%$, compared with the one proposed previously. As a result, the compressive strength increased by $10.8 \%$ at 56 days, while the autogenous shrinkage was similar.

(4) The internal curing using SAP increased the relative humidity inside the hardened concrete body, which was the reason why its autogenous shrinkage can be reduced. And, the effect of internal curing on compressive strength was dependent on the hydration degree, pore structure, and air content. For the internal curing concrete with FA, the entrainment of IC water and the dosage of SAP calculated by the method proposed in this paper were more accurate than equation (1), which can decrease the porosity $(50-10000 \mathrm{~nm})$ and the air void content (less than $200 \mu \mathrm{m})$.

(5) Mineral admixture can change the hydration characteristics and microstructure of concrete, and the method for internal curing water calculation of concrete with SAP must be improved.

\section{Data Availability}

The data used to support the findings of this study are included within the article.

\section{Conflicts of Interest}

The authors declare no conflicts of interest.

\section{Acknowledgments}

This work was supported by the Fundamental Research Project for a New Technical Application from MOT of China (Grant No. 2014319223 070).

\section{References}

[1] X.-m. Kong, Z.-1. Zhang, and Z.-c. Lu, "Effect of pre-soaked superabsorbent polymer on shrinkage of high-strength concrete," Materials and Structures, vol. 48, no. 9, pp. 2741-2758, 2015.

[2] O. M. Jensen and P. F. Hansen, "Water-entrained cementbased materials," Cement and Concrete Research, vol. 32, no. 6 , pp. 973-978, 2002.

[3] D. P. Bentz and K. A. Snyder, "Protected paste volume in concrete," Cement and Concrete Research, vol. 29, no. 11, pp. 1863-1867, 1999.

[4] R. S. Gemma and F. G. Arlindo, "Effects of fine LWA and SAP as internal water curing agents," Journal of Concrete Structures and Materials, vol. 8, pp. 229-238, 2014.
[5] O. M. Jensen and P. F. Hansen, "Water-entrained cementbased materials," Cement and Concrete Research, vol. 31, no. 4, pp. 647-654, 2001.

[6] P. Lura, O. M. Jensen, and K. van Breugel, "Autogenous shrinkage in high-performance cement paste: an evaluation of basic mechanisms," Cement and Concrete Research, vol. 33, no. 2, pp. 223-232, 2003.

[7] B. Bissonnette, P. Pierre, and M. Pigeon, "Influence of key parameters on drying shrinkage of cementitious materials," Cement and Concrete Research, vol. 29, no. 10, pp. 1655-1662, 1999.

[8] D. P. Bentz and O. M. Jensen, "Mitigation strategies for autogenous shrinkage cracking," Cement and Concrete Composites, vol. 26, no. 6, pp. 677-685, 2004.

[9] D. Shen, T. Wang, Y. Chen, M. Wang, and G. Jiang, "Effect of internal curing with super absorbent polymers on the relative humidity of early-age concrete," Construction and Building Materials, vol. 99, pp. 246-253, 2015.

[10] J. Liu, C. Shi, X. Ma, K. H. Khayat, J. Zhang, and D. Wang, "An overview on the effect of internal curing on shrinkage of high performance cement-based materials," Construction and Building Materials, vol. 146, pp. 702-712, 2017.

[11] V.-T.-A. Van, C. Rößler, D.-D. Bui, and H.-M. Ludwig, "Rice husk ash as both pozzolanic admixture and internal curing agent in ultra-high performance concrete," Cement and Concrete Composites, vol. 53, pp. 270-278, 2014.

[12] X. Ma, J. Liu, Z. Wu, and C. Shi, "Effects of SAP on the properties and pore structure of high performance cementbased materials," Construction and Building Materials, vol. 131, pp. 476-484, 2017.

[13] A. Assmann and H. W. Reinhardt, "Tensile creep and shrinkage of SAP modified concrete," Cement and Concrete Research, vol. 58, pp. 179-185, 2014.

[14] B. Craeye, M. Geirnaert, and G. D. Schutter, "Super absorbing polymers as an internal curing agent for mitigation of early-age cracking of high-performance concrete bridge decks," Construction and Building Materials, vol. 25, no. 1, pp. 1-13, 2011.

[15] C. Schröfl, V. Mechtcherine, and M. Gorges, "Relation between the molecular structure and the efficiency of superabsorbent polymers (SAP) as concrete admixture to mitigate autogenous shrinkage," Cement and Concrete Research, vol. 42, no. 6, pp. 865-873, 2012.

[16] D. Gao, R. B. Heimann, and D. B. Alexander, "Box-Behnken design applied to study the strengthening of aluminate concrete modified by a superabsorbent polymer/clay composite," Advances in Cement Research, vol. 9, no. 35, pp. 93-97, 1997.

[17] K. Sikora and A. J. Klemm, "Effect of superabsorbent polymers on workability and hydration process in fly ash cementitious composites," Journal of Materials in Civil Engineering, vol. 27, pp. 1-13, 2015.

[18] C. H. Zhu, Research and Application of Crack Control Technology for Concrete Structures in Arid Sandy Areas, China Academy of Railway Sciences, Beijing, China, 2015.

[19] T. C. Powers and T. L. Brownyard, "Studies of the physical properties of hardened Portland cement paste," Journal of the American Concrete Institute, vol. 43, pp. 101-132, 1947.

[20] T. C. Powers, "Physical properties of cement paste," in Proceedings of the Fourth International Symposium on the Chemistry of Cement, Washington, D.C, USA, October 1960.

[21] T. C. Powers, The Nonevaporable Water Content of Hardened Portland-cement Paste-Its Significance for Concrete Research and its Method of Determination, pp. 68-76, ASTM, West Conshohocken, PA, USA, 1949. 
[22] D. Shen, M. Wang, Y. Chen, W. Wang, and J. Zhang, "Prediction of internal relative humidity in concrete modified with super absorbent polymers at early age," Construction and Building Materials, vol. 149, pp. 543-552, 2017.

[23] A. S. El-Dieb, "Self-curing concrete: water retention, hydration and moisture transport," Construction and Building Materials, vol. 21, no. 6, pp. 1282-1287, 2007.

[24] J. J. Ye, S. G. Hu, F. Z. Wang et al., "Effect of pre-wetted lightweight aggregate on internal relative humidity and autogenous shrinkage of concrete," Journal of Wuhan University of Technology, vol. 21, no. 1, pp. 134-137, 2006.

[25] Y. Wei, Y. Xiang, and Q. Zhang, "Internal curing efficiency of prewetted LWFAs on concrete humidity and autogenous shrinkage development," Journal of Materials in Civil Engineering, vol. 26, no. 5, pp. 947-954, 2014.

[26] Y. Zhang, L. Gao, X. Cai, Q. Li, and X. Kong, "Influences of triethanolamine on the performance of cement pastes used in slab track," Construction and Building Materials, vol. 238, p. $117670,2020$.

[27] American Society for Testing and Materials, Standard Test Method for Microscopical Determination of Parameters of the Air-Void System in Hardened Concrete, ASTM, West Conshohocken, PA, USA, 2016.

[28] J. Zhang, X. Gao, and L. Yu, "Improvement of viscositymodifying agents on air-void system of vibrated concrete," Construction and Building Materials, vol. 239, p. 117843, 2020.

[29] U. H. Jakobsen, C. Pade, N. Thaulow et al., "Automated air void analysis of hardened concrete - a Round Robin study," Cement and Concrete Research, vol. 36, no. 8, pp. 1444-1452, 2006.

[30] N. Neithalath, J. Persun, and A. Hossain, "Hydration in highperformance cementitious systems containing vitreous calcium aluminosilicate or silica fume," Cement and Concrete Research, vol. 39, no. 6, pp. 473-481, 2009.

[31] S. M. Monteagudo, A. Moragues, J. C. Gálvez, M. J. Casati, and E. Reyes, "The degree of hydration assessment of blended cement pastes by differential thermal and thermogravimetric analysis. Morphological evolution of the solid phases," Thermochimica Acta, vol. 592, pp. 37-51, 2014.

[32] S. Igarashi and A. Watanabe, "Experimental study on prevention of autogenous deformation by internal curing using super-absorbent polymer particles," in Proceedings of the international RILEM conference, Lyngby, Denmark, August 2006.

[33] L. P. Esteves, Internal Curing in Cement-Based Materials, Aveiro University, Aveiro, Portugal, 2009.

[34] A. B. Ribeiro, A. Gonçalves, and A. Carrajola, "Effect of shrinkage reduction admixtures on the pore structure properties of mortars," Materials and Structures, vol. 39, no. 2, pp. 179-187, 2006.

[35] E. Sakai, T. Kasuga, T. Sugiyama, K. Asaga, and M. Daimon, "Influence of superplasticizers on the hydration of cement and the pore structure of hardened cement," Cement and Concrete Research, vol. 36, no. 11, pp. 2049-2053, 2006.

[36] Z. W. Wu, "An approach to the recent trends of concrete science and technology," Journal of the Chinese Ceramic Society, vol. 7, pp. 262-270, 1979.

[37] P. K. Mehta and P. J. M. Monteiro, Concrete Microstructure, Properties, and Materials, pp. 120-126, McGraw-Hill, New York, NY, USA, 2008. 